\title{
Kajian Sistem Pendukung Pengambilan Keputusan (DIFURAD) Pada Sistem Kedaruratan Nuklir Kawasan Mediterranean
}

Akhmad Khusyairi, S.T.,M.Eng

P2STPIBN BAPETEN,

a.khusyairi@bapeten.go.id; a.khusyairi@gmail.com

\begin{abstract}
Abstrak - Kajian Sistem Pendukung Pengambilan Keputusan (DIFURAD) Pada Sistem Managemen Kedaruratan Nuklir Kawasan Mediterranean. Sebagian besar Negara-negara Eropa memenuhi kebutuhan energi mereka dengan memanfaatkan energi nuklir. Dalam hal kedaruratan nuklir yang terjadi pada PLTN di Negara-negara Eropa akan memberikan dampak radiologi yang cukup serius di kawasan Mediterranean. Saat ini ENEA telah mengembangkan system pendukung pengambilan keputusan dalam system manajemen kedaruratan nuklir, DIFURAD. Hingga 2013, ENEA telah mengembangkan 2 skenario kecelakaan nuklir yang terjadi lintas perbatasan dan dispersi zat radioaktif ke laut Mediteranian melalui sungai. Kedua skenario yang telah dibangun dapat mensimulasikan kemungkinan dampak radiologi lingkungan dan yang mungkin terjadi pada masyarakat kawasan Mediterranian serta memberikan informasi yang diperlukan dalam manajemen kedaruratan nuklir. Beberapa negara ASEAN saat ini telah memutuskan untuk memanfaatkan teknologi nuklir untuk memenuhi kebutuhan energy listrik mereka, DIFURAD merupakan salah satu model yang dapat digunakan sebagai acuan dalam membangun sistem kedaruratan nuklir regional. Kajian ini dilakukan dengan menggunakanan metode studi literatur.
\end{abstract}

Kata kunci: Kedaruratan nuklir, mitigasi dampak,DIFURAD, instalasi nuklir, Mediterranean

\begin{abstract}
Assessment on Mediterranean Area Decision-Support System (DIFURAD) for Nuclear Emergency Management System. Most European energy demand is supplied by Nuclear Energy. In case of nuclear emergency, European countries nuclear power plant will influence significantly to radiological level of Mediterranean area. Today, ENEA developed Decision Support System for nuclear emergency management system, DIFURAD. Up to 2013, ENEA developed 2 nuclear accident scenarios which are occurred trans-boundary and Mediterranean basin contamination through river. Both scenarios have ability to provide a prompt estimation on population and environment impact which are considered during emergency. Some ASEAN countries decided to produce electricity based on nuclear to supply their electricity demand, DIFURAD is a model which could be used for reference for developing nuclear emergency network system. The method which is used for this assessment was literature study.
\end{abstract}

Key words: nuclear emergency, mitigation, DIFURAD, nuclear installation, Mediterranean.

\section{PENDAHULUAN}

Negara-negara Eropa yang berada pada kawasan Alpine yang terdiri dari 8 negara diantaranya Austria, Slovenia, Switzerland, Liechtenstein, Jerman, Perancis, Italy dan Monaco, tiga diantaranya yaitu Slovenia, Germany, dan France mengoperasikan reaktor nuklir yang ditujukan untuk memenuhi kebutuhan energy listrik mereka. Kemungkinan terjadinya kecelakaan pada reactor nuklir yang dimiliki oleh ketiga Negara tersebut akan memberikan dampak radiologi pada laut Mediterranean. Italia merupakan Negara yang relatif mempunya garis pantai terpanjang di laut Mediterranean, mempunyai kepentingan jika terjadi kedaruratan nuklir pada Negara-negara di kawasan tersebut.

Berdasarkan laporan tahunan Euroatom 2012, berikut Negara-negara Uni Eropa yang memiliki dan mengoperasikan PLTN.

Tabel 1. Negara-negara Uni Eropa yang memiliki PLTN,[7]

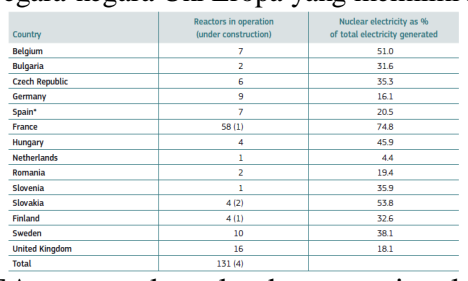

ENEA merupakan lembaga nasional Italia yang mempunyai tugas dan kompetensi melakukan riset dan promosi pemanfaatan energy nuklir. Melalui ENEA, Italia telah mengembangkan system pendukung pengambilan keputusan dalam system kedaruratan nuklir nasional.

\section{TINJAUAN PUSTAKA}

\subsection{Umum}

Berdasarkan laporan tahunan Euratom 2012, terdapat tiga Negara di kawasan Alpine yang memiliki dan mengoperasikan PLTN, yaitu Slovenia, Germany dan France. Ketiga Negara tersebut berada pada daerah selatan Eropa sehingga kawasan dan laut Mediterranean rentan jika terjadi kecelakaan nuklir pada tiga Negara tersebut.

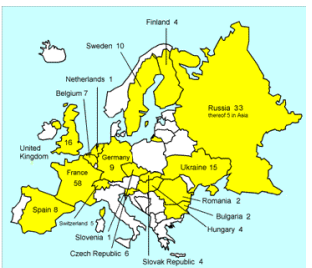

Gambar 1. PLTN yang beroperasi di Eropa,[6]

Slovenia, mempunyai 1 reaktor nuklir untuk pembangkit listrik dengan daya 668 MWe type PWR setara dengan 35\% kebutuhan energy listriknya. PLTN tersebut dibangun pada awal tahun 70-an oleh Pemerintah Yugoslavia dan masuk jaringan listrik nasional pada tahun 1983. PLTN ini merupakan kepemilikan bersama antara Slovenia dan Croatia sebagai warisan bersama dari Yugoslavia[6].

Jerman mempunyai 9 unit PLTN yang masih beroperasi, pada masa pemerintahan Gerhard Schroeder, Pemerintah Jerman memutuskan untuk menutup semua PLTN pada 2020 yang telah memiliki masa operasi 32 tahun [6]. 
Perancis mempunyai 58 unit PLTN yang beroperasi dan 1 unit PLTN sedang dalam tahap konstruksi, sementara itu PLTN yang sedang dalam tahap konstruksi direncanakan akan memberikan kontribusi 1,6 GWe[6]

\subsection{Kecelakaan Nuklir dan Radiasi}

Kecelakaan nuklir adalah setiap kejadian atau rangkaian kejadian yang menimbulkan kerugian nuklir. Kecelakaan radiasi adalah kejadian yang tidak direncanakan, termasuk kesalahan operasi, kerusakan atau kegagalan fungsi alat, atau kejadian lain yang menjurus pada timbulnya dampak radiasi, kondisi paparan radiasi dan/atau kontaminasi yang melampaui batas sebagaimana ditetapkan dalam ketentuan peraturan perundang-undangan[2].

Kecelakaan nuklir dapat mengakibatkan terjadinya pelepasan material radioaktif atau kejadian yang sejenis dimana dapat menghasilkan pelepasan material radioaktiv lintas nasional/negara yang dapat berdampak signifikan terhadap masyarakat, lingkungan atau fasilitas itu sendiri. Beberapa upaya teknis telah dilakukan dan diterapkan guna mereduksi resiko kecelakaan maupun meminimalisasi jumlah radioaktivitas yang terlepas ke lingkungan.

\subsection{DIFURAD}

DIFURAD yang merupakan sistem pendukung pengambilan keputusan yang dikembangkan Italia melalui ENEA. System ini merupakan system pendukung pengambilan keputusan yang berbasis komputer on-line yang khusus dikembangkan oleh ENEA untuk kawasan perairan Mediterranean. System ini berbasis pada peta geospasial untuk memetakan dampak pelepasan zat radioaktiv yang diakibatkan oleh kecelakaan nuklir parah pada PLTN Negara tetangga. DIFURAD mengintegrasikan prediksi model dan data geospasial untuk memetakan difusi radionuklida, definisi skenario dan rencana bencana. System ini dapat melakukan komputasi 6-12 jam setelah kejadian kecelakaan secara akurat dan handal selama 7 hari berturut-turut. System ini juga dirancang khusus untuk melakukan komputasi dan pemetaan dampak jatuhan debu radioaktiv dan sebarannya di wilayah Italia [13].

\section{PEMBAHASAN}

Kondisi geografis Italia yang terletak di bagian selatan benua Eropa dengan garis pantai terpanjang di perairan Mediterranean, $9.226 \mathrm{~km}$, mempunyai potensi terdampak yang diakibatkan oleh kejadian atau kecelakaan PLTN di 3 negara yang terletak di kawasan Alpine serta pembelajaran dari kasus Fukushima pada tahun 2011, memacu Italia untuk membangun system manajemen kedaruratan nuklir lintas Negara untuk melindungi lingkungan dan warganya.

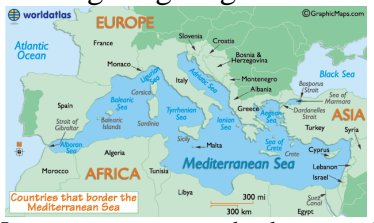

Gambar 2. Negara-negara yang berbatasan dengan Laut Mediterranean [10]

Sementara itu, system pendukung pengambilan keputusan (DSS, Decision Support System) yang telah berkembang di kawasan Uni Eropa adalah RODOS. RODOS dirancang untuk mendukung pengambilan keputusan dalam hal kedaruratan nuklir di wilayah Eropa.

\subsection{ARGOS}

ARGOS pada awalnya dikembangkan dengan penekanan khusus untuk mendukung Danish Emergency Management Agency (DEMA), hal ini terkait dengan kedaruratan yang melibatkan nuklir pada kecelakaan PLTN maupun instalasi nuklir lainnya. Otoritas

Fitur dasar yang dimiliki ARGOS adalah kemampuan running, prediksi dan menampilan visualisasi hasil dari pemodelan dispersi atmosferik. Kemampuan dasar ARGOS ini didukung oleh data base meteorology dan data terkait dengan data kecelakaan yang melibatkan CBRN.

Saat ini ARGOS telah diintegrasikan dengan beberapa model eksternal, diantaranya adalah:

- "Risoe Meso-scale Puff Model" (RIMPUFF), yang digunakan untuk memodelkan disperse atmosferik dan melakukan kalkulasi sebaran.

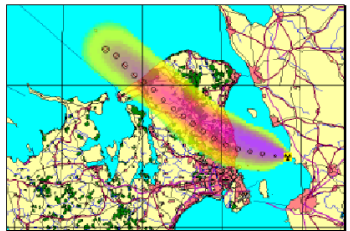

Gambar 3 Hasil Pemodelan Dispersi Atmosferik RIMPUFF[4]

- "Food and Dose Module" (FDM) merupakan model yang digunakan untuk melakukan perhitungan estimasi dosis pada daerah pedesaan

- "Agricultural Counter-measure Program" (AGRICP), merupakan software pengganti FDM namun dapat melakukan perhitungan efek dari countermeasures yang dilakukan dalam upaya mitigasi dampak.

- "European Model for Inhabited Areas" (ERMIN) merupakan modul yang digunakan dalam perhitungan kontaminasi berbagai permukaan di lingkungan pemukiman, dosis yang diterima masyarakat dan dampak dari countermeasures yang dilakukan.

- HeavyGas model, merupakan model yang digunakan dalam perhitungan dispersi atmosferik gas berat .

\subsection{RODOS}

Beberapa kebutuhan yang muncul dari pengalaman Eropa terkait dengan kecelakaan Chernobyl, diantaranya adalah:

- Perlunya sebuah respon lintas Eropa yang lebih koheren dan terharmonisasi dalam setiap tahapan kecelakaan.

- Pertukaran informasi dan data dalam kedaruratan yang diperlukan negara tetangga guna melakukan tindakan yang tepat dan efektif.

- Perlu dibuat suatu system atau sumber daya atau sarana dan prasarana yang lebih baik dan mencegah terjadinya duplikasi system.

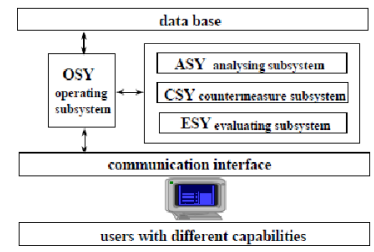

Gambar 4. Arsitektur Konseptual RODOS[5]

Real-time On-line Decision Support system, RODOS mulai dikembangkan pada tahun 1989 yang merupakan system on line yang dikembangkan untuk menyediakan informasi secara konsisten dan komprehensif tentang kondisi radiologi saat ini 
(saat terjadi kecelakaan) dan yang akan datang terkait dengan kasus kecelakaan nuklir di Eropa. System ini dapat membantu pengambilan keputusan dalam upaya mitigasi dampak. Oleh karena itu pemodelan dan data base yang digunakan RODOS dapat disesuaikan dengan kebutuhan penggunanaan sesuai dengan karakteristik tapak dan instalasi serta keragaman geografis, iklim dan lingkungan di Eropa.

\subsection{DIFURAD}

DIFURAD didesain untuk lebih fokus pada pemodelan dan observasi untuk kawasan Mediterranean. System ini dilengkapi dengan pemodelan atmosferik dan gidrologi yang dirancang secara real time dan hasil pemodelan ditampilkan dalam system WebGIS dalam beberapa lapisan data peruntukan lahan dan sosio-ekonomi untuk memberikan gambaran terhadap wilayah yang terkena dampak baik terhadap populasinya maupun resiko aktivitas ekonomi. System ini dirancang sebagai alat untuk membantu pengambilan keputusan oleh pihak berwenang dalam managemen kedaruratan dan manajemen pasca kecelakaan nuklir. Tujuan jangka panjang pengembangan DIFURAD adalah untuk mendukung pelayanan terkait dengan manajemen resiko dalam hal terjadinya pelepasan radionuklida ke atmosfer atau ke lautan, integrasi dengan beberapa model dan tool kajian dampak dalam GIS yang berbasis DSS untuk manajemen resiko dan kedaruratan pada infrastruktur kritis. Tugas system manajemen kedaruratan nuklir untuk mengkaji:

- Sumber radiasi

- Dispersi zat radioaktif yang terlepas ke atmosfer

- Transport jarak jauh debu radioaktif di atmosfer

- Deposisi di permukaan tanah

- Dispersi radionuklida yang terlepas ke lingkungan perairan baik secara langsung maupun jatuhan dari atmosfer

- Konsentrasi radionuklida pada matrik makanan di laut

- Dosis populasi.

DIFURAD menggunakan 2 prosedur yang berbeda dan saling melengkapi dalam melakukan kajian disperse dan emisi zat radioaktif:

- Rapid Procedure, dalam prosedur ini dilakukan estimasi dan simulasi disperse zat radioaktif yang berdekatan dengan episenter.

- More Sophisticated Procedure, dalam prosedur ini, dilakukan perhitungan atau penentuan jumlah emisi dan disperse secara akurat dalam skala regional.

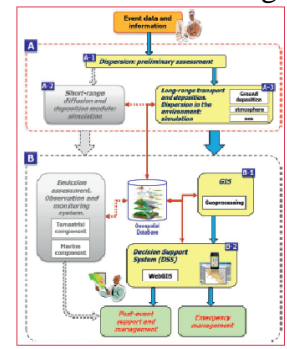

Gambar 5. Diagram Alur Operasi DIFURAD [13]

\subsection{Kondisi ASEAN}

Indonesia merencanakan akan mengoperasikan sebanyak 4 unit PLTN pada tahun 2024[16], Philipina akan menggunakan nuklir untuk memenuhi pasokan energy mereka sebanyak 5\% pada 2030, Pemerintah Malaysia pada tahun 2010 telah mengadopsi kebijakan nuklir[15].
Sementara itu Vietnam merencanakan akan membangun 13 unit PLTN selama 2 dekade kedepan [11].

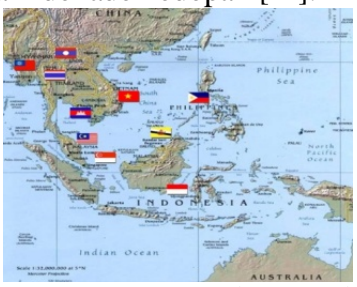

Gambar 6. Peta Negara-negara Anggota ASEAN[14].

Berdasarkan data yang dilansir [3], Pemerintah Malaysia menyatakan akan membangun 2 PLTN dengan daya masingmasing 1000 MWe. Pemerintah Malaysia mengidentifikasi 7 calon lokasi tapak PLTN yang tersebar di Semenanjung Malaysia diantaranya 1 calon tapak di negara bagian Kedah, 2 calon tapak di negara bagian Perak, 2 calon tapak di negara bagian Terengganu dan 2 calon tapak di negara bagian Johor. Setidaknya terdapat 5 calon tapak yang berada di pesisir pantai.

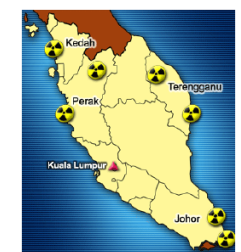

Gambar 7. Calon lokasi tapak PLTN Malaysia [3]

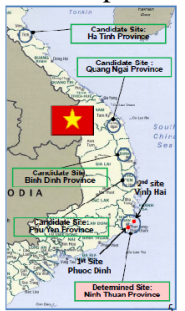

Gambar 8. Calon Lokasi Tapak PLTN Vietnam [13].

Berdasarkan laporan yang dilansir WNA [17] Pemerintah Vietnam merencanakan pembangunan 14 unit PLTN.

Tabel 2. Rencana Pembangunan PLTN Vietnam [17].

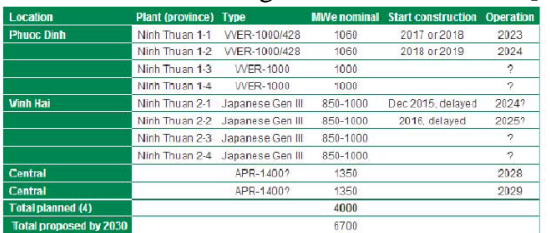

Berdasarkan informasi yang dilansir [12], pada tahun 2010 Pemerintah Thailand telah menetapkan Rencana Pembangunan Energy 2010 untuk 20 tahun kedepan dan akan dibangun 5 unit PLTN. Thailand mempunyai 9 calon tapak PLTN yang sebagian besar calon lokasi tapak tersebut berada dipesisir pantai.

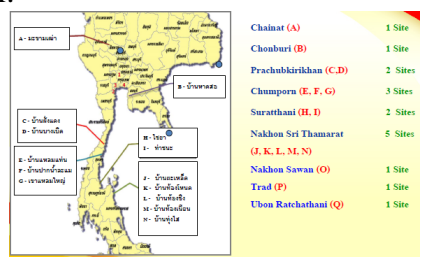

Gambar 10 Calon lokasi tapak PLTN Thailand [9]

Berdasarkan informasi tersebut, pada tahun 2020-an beberapa PLTN di ASEAN sudah mulai beroperasi, dimana Malaysia, 
Vietnam dan Thailand mempunyai potensi membangun PLTN di kawasan pesisir pantai.

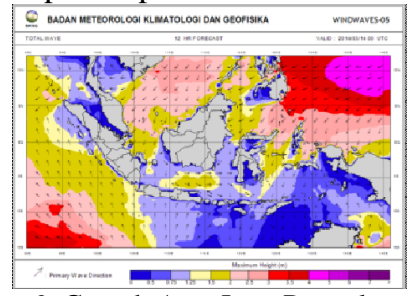

Gambar 9. Contoh Arus Laut Permukaan Sesaat [1]

Dalam kondisi kedaruratan yang mungkin terjadi pada PLTN di kawasan ASEAN, dispersi zat radioaktif dapat berdampak pada teritorial Indonesia. Sebagai contoh, berdasarkan data yang diambil dari BMKG pada 14 Maret 2014, prediksi arah arus laut yang terjadi dikawasan ASEAN menuju perairan Indonesia, maka dapat diperkirakan deposisi kontaminasi dan dispersi zat radioaktiv akibat kecelakaan nuklir di kawasan ASEAN arahnya menuju wilayah Indonesia. Beberapa DSS yang telah diimplementasikan baik di kawasan Eropa maupun Kanada dapat diadopsi untuk dilakukan penelitian dan pengembangan lebih lanjut untuk digunakan sebagai rujukan dalam mengembangkan system pendukung pengambilan keputusan dalam manajemen kedaruratan nuklir baik pada tingkat nasional maupun regional ASEAN.

\section{KESIMPULAN}

System pendukung pengambilan keputusan (DSS) dalam manajemen kedaruratan nuklir yang telah dikembangkan oleh Kanada dan beberapa Negara Eropa merupakan antisipasi penanganan kedaruratan yang mungkin terjadi. Pada awalnya pembangunan system kedaruratan nuklir Italia terinisiasi oleh adanya kecelakaan Fukushima yang terjadi pada tahun 2011 dimana dampak radiologis yang terdispersi ke perairan baik akibat jatuhan debu radioaktif maupun kontaminasi lewat jalur air laut dapat berdampak pada Negara sekitar Jepang. Saat ini system kedaruratan nuklir Italia masih terbuka untuk dikembangkan lebih lanjut dan difokuskan pada perairan Mediterranean. Beberapa Negara ASEAN telah memutuskan untuk memanfaatkan teknologi nuklir untuk memenuhi kebutuhan energy listrik nasionalnya, hal ini perlu mendapat perhatian yang serius bagi Negara-negara anggota ASEAN untuk mengantisipasi terjadinya kedaruratan nuklir di kawasan ASEAN. Indonesia harus melakukan inisiasi dalam proses pembangunan dan pengembangan system pendukung pengambilan keputusan dalam manajemen kedaruratan nuklir kawasan ASEAN, mengingat resiko yang mungkin terjadi jika Negara-negara ASEAN membangun PLTN. Jaringan sistem pendukung pengambilan keputusan dalam manajemen kesiapsiagaan dan kedaruratan nuklir on-line lintas negara yang berbasi IT dan didukung oleh interface dengan badan meteorologi, radiologi dan hidrologi baik lokal, nasional maupun lintas negara perlu segera dirintis.

\section{DAFTAR PUSTAKA}

[1.] Badan Meteorologi Klimatologi dan Geofisika. (2014, March 14). Badan Meteorologi Klimatologi dan Geofisika. Dipetik March 14, 2014, dari Badan Meteorologi Klimatologi dan Geofisika: http://maritim.bmkg.go.id/index.php/main/prakiraan_gel ombang_12jam
[2.] BAPETEN. (2010). PERATURAN KEPALA BADAN PENGAWAS TENAGA NUKLIR No 1 Tahun 2010. Jakarta: BAPETEN.

[3.] Chie, K. G. (2012, July 19). Gov't Indentifies 7 sites for NPP, Says NGO. Dipetik March 14, 2014, dari Suara Serawak: http://www.barubian.net/2012/07/govtidentifies-7-sites-for-nuclear.html

[4.] DEMA. (2011). ARGOS CBRN, White Paper. Birkerød: DEMA.

[5.] Ehrhardt, J. (2005). Improvement_Extension and integration of Operational Desision Supprot Systems for Nuclear Emergency Management (DSSNET). Karlsruhe: Forschungszentrum Karlsruhe $\mathrm{GmbH}$.

[6.] European Nuclear Society. (2014, March 10). Nuclear Power Plant in Europe. Dipetik March 12, 2014, dari European Nuclear Society: http://www.euronuclear.org/

[7.] European Union. (2012). Annual Report Euratom Supply Agency. Luxembourg: European Union.

[8.] Izumo, A. (2011, February). IAEA. Dipetik March 14, 2014, dari IAEA http://www.iaea.org/NuclearPower/Downloadable/Meeti ngs/2011/2011-02-TM-WS-Vienna/Day3/Izumo_VIETNAM.pdf

[9.] Kalayanamitr. (2012). Status of Nuclear Energy Project in Thailand. Unknown: Electricity Generating Authority of Thailand.

[10.] Let's Do It World. (2012, October 17). Mediterranean Action ! Dipetik March 12, 2014, dari Let's Do It: http://www.letsdoitworld.org/

[11.] nuclear.com. (2012, June 30). Vietnam news. Dipetik October 26, 2013, dari Nuclear.com: www.nuclear.com

[12.] Patchimpattapong, A. (2010, June 5). Thai Professionals Conference. Dipetik March 14, 2014, dari Nuclear Society of Thailand: http://www.nst.or.th/npower/1-Nuclear.pdf

[13.] R. Delfanti, M. P. (2013, April). A Risk Analysis and Decision Support System for Nuclear Accidents in the Mediterranean Area. Energia, Ambiente $e$ Innovazione, hal. 43-51.

[14.] The South East Asia Weekly. (2012, April 13). NGos in ASEAN urge more discussion on ASEAN Human Right Body. Dipetik March 14, 2014, dari The South East Asia Weekly: http://www.thesoutheastasiaweekly.com/ngos-in-aseanurge-more-discussion-on-asean-human-right-body/

[15.] Utama, N. A. (2012). Power Generation Optimization in ASEAN by 2030. Energy and Power Engineering , 226-232.

[16.] Vivoda, V. (2013, May 16). After Fukushima. Dipetik October 26, 2013, dari East Asia Forum: www.eastasiaforum.org

[17.] World Nuclear Association. (2014, February). Nuclear Power in Vietnam. Dipetik March 14, 2014, dari World Nuclear Association: http://www.worldnuclear.org/info/Country-Profiles/Countries-TZ/Vietnam/ 